\title{
Empirical Research on Key Factors in Environmental Protection Based Ecotourism of B\&B
}

\author{
Hao-Cheng Huang ${ }^{1 *}$, Yeng-Horng Perng ${ }^{1}$ \\ ${ }^{1}$ Department of Architecture, National Taiwan University of Science and Technology, TAIWAN
}

Received 15 May 2017 - Revised 8 September 2017 - Accepted 13 October 2017

\begin{abstract}
The enhancement of national living standard and the practice of two-day weekend have tourism activity become essential in people's life in Taiwan. Along with increasing tourists, it becomes a tough problem in the environment load. The ideas of green consumption and even ecotourism are therefore successively proposed. However, not every visitor is willing to sacrifice the fun and comfort in the tour for environmental protection. The effect of environmental measures on visitors' perceived play value is therefore analyzed in this study. Visitors to ecological touring spots of B\&B in eastern Taiwan are selected as the research samples in this study. Total 500 copies of questionnaire are distributed and collected on-site, and 412 valid copies are retrieved, with the retrieval rate $82 \%$. The research results are summarized as following: (1) Environmental measures present positively significant effects on perceived value of tourism. (2) Environmental responsibility shows positively remarkable effects on environmental measures. (3) Environmental responsibility reveals positively notable effects on perceived value of tourism. Finally, suggestions are proposed, expecting to help the government, relative departments, and businesses understand the cognition and needs of visitors, through the analysis of visitors to ecotourism of $B \& B$, and carefully think and weigh between economy and environment.
\end{abstract}

Keywords: tourism activity, B\&B (Bed and breakfast), ecotourism, local humanistic characteristics

\section{RESEARCH BACKGROUND AND MOTIVATION}

Economy is rapidly developed globally to enhance the national income and consuming capacity. The improvement of living conditions also changes people's value tending to purchasing materials and necessities with package and cultivating the habit of discarding after use. Nonetheless, people, when seeking pleasure, often ignore that the nature is ruthlessly damaged and polluted and the load is limited. Continuous earthquakes, tsunamis, and climate anomaly are the warning from the nature (Hsueh, 2012). The rising environmental awareness in past years has people start to think of coexisting with the earth. The ideas of green management, sustainable resources, and proenvironment are therefore proposed (Hsueh, 2015). When the living standard is promoted, people start to pursue higher-quality material needs and mind contentment; recreation activity is the product under such a time and space background. Nevertheless, the counterattack of the nature resulted from the increasing number of tourists annually and the overuse of ecological environment has people realize the importance of co-existence. To seek the method for giving considerations to both, the ideas of 'green tourism and ecotourism of B\&B' are emerged.

The so-called green tourism and ecotourism of $B \& B$ are the types of tourism with the least impact on the environment. It insists on the spirit of energy saving and carbon reduction and enjoying the experience in ecology and humanity; environmental measures are the practical execution of green tourism. Although the issue of environmental protection is popular, not every visitor is willing to sacrifice the fun and comfort in the tour to respond to environmental protection. From the aspect of consumers, the effect of environmental measures on visitors' perceived play value is analyzed to help the government, relative departments, and businesses understand visitors' cognition and needs and to carefully think and weigh between economy and environment. 


\section{Contribution of this paper to the literature}

- To give considerations to the development of ecotourism of B\&B and environmental protection, the government should formulate complete ecotourism regulations, containing environmental measures being practiced in touring areas.

- The practice of environmental measures could enhance visitors' perceived value of tourism and further win the competitive advantages. The increasing green consumers and eco-tourists in past years respond to the trend of environmental protection.

- The ideas of green consumption and even ecotourism are gradually proposed; however, not every visitor is willing to sacrifice the fun and comfort in the tours to respond to environmental protection.

- Environmental protection, environmental responsibility, perceived value, and local culture and natural ecology are the best strategies for sustainable green tourism.

\section{LITERATURE AND REVIEW}

\section{Environmental Measures}

Kapoor (2015) proposed green tourism as the overall consideration of economy, ecology, and society, rather than simply economy, for the development of environmental tourism. Pikturnienè and Mackelaite (2013) regarded green tourism as the development of tourism industry achieving the coexistence with the nature. Bailey and Mattei (2013) considered the meaning of green tourism as ecological responsibility, local economic vitality, culture sensitivity, and experiential richness and proposed the idea of 3R, namely Reduce, Recycle, and Reuse. Furthermore, regarding cultural ecotourism in green tourism, Wallace and Russell (2004) considered that cultural and ecotourism could be employed by local people to build an empowered and sustainable future in similar settings elsewhere. Ellis (2014) defined green management as introducing the principle of sustainable development into tourism activity so that the production and management of tourism industry developed towards low pollution, low consumption, and high value added, gave considerations to the protection and development of culture, acquired competitive advantages, through producing and managing green tourism products, in green market, and attracted tourists' needs for green consumption. The following principles were further proposed, including (1) protection principle: giving considerations to both environmental protection and cultural protection, (2) humanoriented management principle: people oriented to implement the coordinate development between people and environment, among people, and ego, and (3) guidance principle: guidance of the government, participation of experts, participation of communities, and participation of conditional enterprises. Munro (2012) defined green tourism as the tourism pattern with the least impact, from visitors, on the environment, the insistence on the spirit of energy saving and carbon reduction, and the experience in enjoying ecology and humanity. Laitos (2012) defined green tourism as the idea and practice of 'environment friendly' and stressed on the importance of the correspondence of tourism industry and relevant measures; besides, the government had to establish a standard certification system.

Referring to the research of Chen and Tung (2014) on the tourism in Yunnan villages, green tourism management in this study is divided into the dimensions of management, including green culture, green service, green community, and green consumption, and technology, covering treatment of rubbish, emission, and waste, green construction, and green energy. Technology is the practiced environmental measure.

\section{Perceived Value of Tourism}

Perceived value has been used for replacing service quality in past years, as it takes consumers' 'sacrifice' into account. The value of a product or service would be higher when customers perceive the received utility larger than the sacrifice. Besides, perceived value could eliminate the gap of high service quality but low consumer satisfaction (Kill, 2014). Cullinan (2013) regarded customer value as the perceived quality or utility of products relative to the paid price as the sacrifice. The definition of value weighed by 'take' and 'give' in the transaction was regarded as the ratio of 'quality' and 'price' or the choice result in marketing. It was the overall judgment and evaluation. Boyd (2012) defined perceived value as the evaluation of consumers' perceived product or service, i.e. the exchange between perceived benefit and perceived cost. Zeithaml also divided four types of consumers' perceived value, including (1) value as low prices, (2) value as expected products, (3) value as the acquired quality for the paid price, and (4) value as acquiring for the paying. The acquisition of value contained significant internal attributes, external attributes, cognitive quality, and other variables, while the sacrifice of perceived value covered monetary price and non-monetary price, such as time, energy, and effort. Icek, Nicholas, Sana, and Nicole (2011) briefly explained consumers' perceived value as the perceived quality or benefit of products relative to the sacrifice 
for the paid price. O'Dea (2014) regarded perceived value as the evaluation between consumers' perceived preference and product attributes, attribute performance, and use outcome in certain use situations to help customers achieve the objective. Koller, Floh, and Zauner (2011) proposed perceived value as the ratio between acquired benefits and the sacrifice cost of a provider. Pradeep (2012) considered that perceived value was a subjective structure for different time and culture among consumers as well as a series of dynamic variables of experience before the purchase, during the purchase, during the use, and after the use. He and Li (2010) regarded perceived value as the drive in consumers' consumption behaviors and the net perceived utility of consumers acquired from products or service. Perceived value is also an important factor in B\&B receiving good word-ofmouth. Chen, Lin, and Kuo (2013) indicated that word-of-mouth was found to be the most effective advertising channel for B\&B accommodation choice. Aiming at green-energy vehicles, Young, Hwang, McDonald, and Oates (2010) referred to the dimensions of perceived value proposed by Sheth et al. and revised them into (1) functional value, (2) emotional value, (3) economic value, and (4) social value. Based on tourism properties, the dimensions of perceived value of tourism in this study, by referring to the definition of Han, Hsu, and Sheu (2010), contains functional value, emotional value, and social value.

Environmental responsibility. Jamal's research (2011) on ecological environment revealed that environmental damage was not simply attributed to enterprises, but consumers' consumption behaviors and treatment after use also resulted in great effects on the environment. Consumers therefore should regard environmental protection as personal responsibility. DeWaters (2011) proposed environmental responsibility as a person being aware of environmental problems and taking relevant actions so that the environmental benefits were the prior consideration in the consumption. Consumers with environmental awareness presented sensitive attitudes towards environmental pollution, resource waste, and rights of descendants. Stone (2010) indicated that environmental responsibility of consumption referred to consumers with awareness of limited resources taking responsibility for the environment. The effects of consumer' environmental responsibilities towards attitudes of the green advertising: A sample in Eskisehir Kravchenko, Chowdhury, and Bhuiyan (2013) proposed that consumers with environmental responsibility had the lifestyle without damaging the environment, or with the least damage. Referring to the Universal Declaration of Consumer Rights published by United Nations in 1985, Küker (2012) considered that consumers had the rights to acquire information, education, health, safety, damage compensation, and healthy environment. It promoted the correct use of environment and covered the idea of sustainable development. Mudd (2011) argued that both enterprises and consumers should have environmental responsibility. The idea of green consumption was proposed under limited resources and continuous advance of society that people should think of it and put it into practice.

Referring to Chen and Peng (2012), consumers' environmental responsibility in this study is divided into environmental awareness and environmental behavior.

(1) Environmental awareness: concerning environmental issues and regarding it as personal responsibility.

(2) Environmental behavior: i.e. environmental protection/green consumption behaviors, selecting products without or with less pollution to the environment, treating the remainders with environmental methods after the use, encouraging others to use environmental products or engage in environmental protection related behaviors.

\section{Research Hypothesis}

Wells, Ponting, and Peattle (2011) mentioned that visitors could directly and rapidly perceive the environmental quality of destinations and the product or service utility in the tourism process to further generate perceived value. Some visitors might consider a tour being healthy, clean, and harmless when the touring spots implementing environmental measures, while others might not be willing to sacrifice the travel convenience and comfort for responding to environmental protection. From the aspect of consumers, Wager (2014) pointed out the importance of discussing the effect of the practice of environmental measures in touring spots on visitors' perceived value of tourism. Accordingly, the following hypothesis is proposed in this study.

H1: Environmental measures present positively significant effects on perceived value of tourism.

Ethics is the moral relation among people, while environmental ethics is the moral relation between people and natural environments, including personal belief in the environment and attitudes and value to environment. It therefore could be the ethic responsibility between humans and natural environments (Wyman, 2010). Voigt (2013) proposed that consumers' environmental responsibility should be measured with the attitudes, personality, value, lifestyle, family structure, social level, culture, and consumption behaviors; it was important for consumers presenting environmental awareness in the consumption process. Wood (2014) pointed out the emphases of ethics that everyone was a part of life community, should take the responsibility for others and nature as well as present and future generations, and had to respect and protect such basic rights to live. The following hypothesis is further proposed in this study. 
H2: Environmental responsibility shows positively remarkable effects on environmental measures.

Kim, Yun, and Lee (2014) mentioned that a consumer with environmental responsibility would reflect the environmental awareness on the consumption behaviors, i.e. generating environmental protection/green consumption behaviors. With personal perceived responsibility for environmental problems, consumers would cultivate active and positive attitudes towards environment and actively participate in environmental movements. The product or service value would be higher when customers perceive the received utility larger than the sacrifice. Consumers perform the perceived responsibility for environment and resources on the perception of environmental issues, the concern about environmental issues, being optimistic to environmental issues, and the sense of responsibility for global sustainable development (Wray-Lake, Flanagan and Osgood, 2010). In this case, consumers with more environmental responsibility would have higher perceived value of ecotourism and reflect the environmental awareness on the consumption behaviors. The following hypothesis is proposed in this study.

H3: Environmental responsibility reveals positively notable effects on perceived value of tourism.

\section{SUBJECT AND METHOD}

Research subject. Visitors to ecotourism spots of B\&B with local humanistic characteristics in eastern Taiwan are selected as the research samples. Total 500 copies of questionnaire are distributed and collected on-site, and 412 valid copies are retrieved, with the retrieval rate $82 \%$. Eastern Taiwan covers Yilan, Hualien, and Taitung, is next to the Pacific Ocean and the area with natural ecological environment and the best air quality in Taiwan. The rising environmental awareness in past years has the development of Bed and Breakfast with local cultural characteristics and natural ecological environment become the trend. The ecological tour in Maqaw National Park in Yilan County is popular with the public and the best field for the ecotourism of parents and children. Maqaw National Park presents diversified natural ecology and trees, such as Yuanyang Lake Nature Reserve and Ci-lan Major Wildlife Habitat. Cypress forest in Chi-lan Mountain is located in intermediate and high altitude that the area becomes an island-type isolated ecological environment because of high peaks, deep valley, and sufficient rain and fog. Rare gymnosperms therefore are associated with cypress forests, such as Arcto-Tertiary epibiotic plants of Taxus chinensis, Taiwania cryptomerioides, Luanta fir, and Cephalotaxus wilsoniana Hayata. The long-term isolation and evolution forms endemic species in Taiwan. Such rare needle gymnosperm groups have experienced the succession from millions of years to billion years that they could be 'living fossil trees', present indicative status on ecological evolution, and conform to the eighth item of criteria for World Heritage. Chi-lan Mountain is full of water and is covered with clouds and fog that it is the so-called 'fog forest' in botanical community. The natural ecosystem in this area is called 'temperate mountain needle forest community' in academia. The warm, wet, and rainy climate has resulted in diversified composition in the plant society. In terms of the species diversity, the variety of plants is huge in which there are endangered and precious species. Under such rare needle forest, Formosan black bears, Formosan serow, and Muntjac are discovered. The area becomes the habitat heaven for rare wild animals in Taiwan that it presents the value of research and conservation and conforms to the tenth item of criteria for World Heritage.

\section{EMPIRICAL RESULT}

Regression Analysis is utilized for understanding the effects of environmental measures and environmental responsibility on perceived value of tourism.

Regression analysis of environmental measures and perceived value of tourism. Regression Analysis is applied in this study to test the hypothesis and theoretical structure. The first regression tests the effect of environmental measures on functional value. The results reveal positive effects of management and technology on functional value $(\beta=1.946, p=0.012 ; \beta=2.325, p=0.000)$. The second regression tests the effect of environmental measures on emotional value. The results show positive effects of management and technology on emotional value $(\beta=1.838, p=0.021 ; \beta=1.746, p=0.035)$. The third regression tests the effect of environmental measures on social value. The results appear positive and notable effects of management and technology on social value $(\beta=2.162, \mathrm{p}$ $=0.000 ; \beta=2.431, p=0.000)$, Table 1 . Hypothesis 1 therefore is supported. 
$\underline{\text { Table 1. Regression Analysis of Environmental Measures on Perceived Value of Tourism (Data source: Self-organized in This Study) }}$

\begin{tabular}{|c|c|c|c|c|c|c|}
\hline \multirow{3}{*}{$\begin{array}{l}\begin{array}{l}\text { Dependent variable } \rightarrow \\
\text { Independent variable } \downarrow\end{array} \\
\text { Environmental measures } \\
\end{array}$} & \multicolumn{6}{|c|}{ Perceived value of tourism } \\
\hline & \multicolumn{2}{|c|}{ Functional value } & \multicolumn{2}{|c|}{ Emotional value } & \multicolumn{2}{|c|}{ Social value } \\
\hline & $\beta$ & $\mathrm{P}$ & $\beta$ & $\mathrm{P}$ & $\beta$ & $P$ \\
\hline Management & $1.946^{\star}$ & 0.012 & $1.838^{*}$ & 0.021 & $2.162^{\star *}$ & 0.000 \\
\hline Technology & $2.325^{\star *}$ & 0.000 & $1.746^{\star}$ & 0.035 & $2.431^{* \star}$ & 0.000 \\
\hline $\mathrm{F}$ & \multicolumn{2}{|c|}{13.442} & \multicolumn{2}{|c|}{18.623} & \multicolumn{2}{|c|}{23.521} \\
\hline$R^{2}$ & \multicolumn{2}{|c|}{0.183} & \multicolumn{2}{|c|}{0.217} & \multicolumn{2}{|c|}{0.244} \\
\hline Adjusted $\mathrm{R}^{2}$ & \multicolumn{2}{|c|}{0.164} & \multicolumn{2}{|c|}{0.198} & \multicolumn{2}{|c|}{0.221} \\
\hline
\end{tabular}

Table 2. Regression Analysis of Environmental Responsibility on Environmental Measures (Data source: Self-organized in This Study)

\begin{tabular}{|c|c|c|c|c|}
\hline \multirow{3}{*}{$\begin{array}{c}\begin{array}{c}\text { Dependent variable } \rightarrow \\
\text { Independent variable } \downarrow\end{array} \\
\text { Environmental responsibility } \\
\end{array}$} & \multicolumn{4}{|c|}{ Environmental measures } \\
\hline & \multicolumn{2}{|c|}{ Management } & \multicolumn{2}{|c|}{ Technology } \\
\hline & $\beta$ & $\mathrm{P}$ & $\beta$ & $P$ \\
\hline Environmental awareness & $2.034^{\star \star}$ & 0.000 & $2.268^{\star *}$ & 0.000 \\
\hline Environmental behavior & $2.132^{\star *}$ & 0.000 & $2.375^{\star *}$ & 0.000 \\
\hline $\mathrm{F}$ & \multicolumn{2}{|c|}{24.583} & \multicolumn{2}{|c|}{28.316} \\
\hline $\mathrm{R}^{2}$ & \multicolumn{2}{|c|}{0.251} & \multicolumn{2}{|c|}{0.273} \\
\hline Adjusted $\mathrm{R}^{2}$ & \multicolumn{2}{|c|}{0.226} & \multicolumn{2}{|c|}{0.248} \\
\hline
\end{tabular}

Table 3. Regression Analysis of Environmental Responsibility on Perceived Value of Tourism (Data source: Self-organized in This Study)

\begin{tabular}{|c|c|c|c|c|c|c|}
\hline \multirow{3}{*}{$\begin{array}{c}\begin{array}{c}\text { Dependent variable } \rightarrow \\
\text { Independent variable } \downarrow\end{array} \\
\text { Environmental responsibility }\end{array}$} & \multicolumn{6}{|c|}{ Perceived value of tourism } \\
\hline & \multicolumn{2}{|c|}{ Functional value } & \multicolumn{2}{|c|}{ Emotional value } & \multicolumn{2}{|c|}{ Social value } \\
\hline & $\beta$ & $\mathrm{P}$ & $\beta$ & $\mathrm{P}$ & $\beta$ & $\mathrm{P}$ \\
\hline Environmental awareness & $2.078^{* *}$ & 0.000 & $1.736^{*}$ & 0.032 & $2.142^{\star *}$ & 0.000 \\
\hline Environmental behavior & $2.328^{* *}$ & 0.000 & $1.963^{*}$ & 0.011 & $2.467^{* \star}$ & 0.000 \\
\hline $\mathrm{F}$ & 17.634 & & 22.388 & & & \\
\hline$R^{2}$ & 0.212 & & 0.273 & & & \\
\hline Adjusted $\mathrm{R}^{2}$ & 0.186 & & 0.249 & & & \\
\hline
\end{tabular}

Regression analysis of environmental responsibility and environmental measures. Regression Analysis is further used for testing the hypothesis and theoretical structure. The first regression tests the effect of environmental responsibility on management. The results present positive and negative effects of environmental awareness and environmental behavior on management $(\beta=2.034 . p=0.000 ; \beta=2.132, p=0.000)$. The second regression tests the effect of environmental responsibility on technology. The results reveal positively and negatively significant effects of environmental awareness and environmental behavior on technology $(\beta=2.268, p$ $=0.000 ; \beta=2.375, p=0.000$ ), Table 2 . As a result, hypothesis 2 is supported.

Regression analysis of environmental responsibility and perceived value of tourism. Regression Analysis is applied in this study to test the hypothesis and theoretical structure. The first regression tests the effect of environmental responsibility on functional value. The results show positive effects of environmental awareness and environmental behavior on functional value $(\beta=2.078, p=0.000 ; \beta=2.328, p=0.000)$. The second regression tests the effect of environmental responsibility on emotional value. The results reveal positively and negatively remarkable effects of environmental awareness and environmental behavior on emotional value $(\beta=1.736, p=$ $0.032 ; \beta=1.963, p=0.011$ ). The third regression tests the effect of environmental responsibility on social value. The results present positively and negatively significant effects of environmental awareness and environmental behavior on social value $(\beta=2.142, p=0.000 ; \beta=2.467, p=0.000)$, Table 3. Accordingly, hypothesis 3 is supported.

\section{CONCLUSION}

The research results show positively remarkable effects of environmental measures on perceived value of tourism. In other words, visitors would perceive the higher value of the entire tour when the better environmental measures in touring spots are perceived. It reveals that people would take environmental protection into account when pursuing tourism quality and value. It is the performance of green economy activity, environmental responsibility, and social justice. B\&B combing with ecotourism should emphasize perceived value of tourism, 
covering enhancing visitors' perceived value and practicing environmental measures. In addition to ecological conservation, environmental measures could be practiced from visitors' food, clothing, housing, transportation, and education to shopping, and justice. In this case, the insistence on the idea of green tourism and the practice of environmental measures in touring areas are the best solution for the increase of tourism population and environmental load. Consumers' environmental responsibility presents positively notable effects on environmental measures and perceived value of tourism. That is, consumers with stronger environmental responsibility would perceive the practice of environmental measures in touring areas to further affect the better perceived value of tourism. It reveals the stronger consumers' green consumption, the more positive support to green tourism. For this reason, the success of the ecotourism of $B \& B$ with environmental measures requires negative request on visitors' correspondence and positive promotion as well as the cultivation of fundamental environmental responsibility.

\section{SUGGESTION}

Aiming at the results and conclusion, practical suggestions are proposed in this study.

1. To give considerations to the development of ecotourism of $B \& B$ and environmental protection, the government should formulate complete ecotourism regulations, containing environmental measures being practiced in touring areas, the correspondence of visitors, the evaluation standard, and award and punishment measures, and timely provide counseling and subsidies. On the other hand, the cultivation of consumers' environmental responsibility is tightly related to the success of environmental measures. In addition to negatively ban lawbreakers, the government has to positively promote and market environmental protection, and even practice it from children's education. The combination of consumers' concept of responsibility and ecotourism is the fundamental method.

2. The practice of environmental measures could enhance visitors' perceived value of tourism and further win the competitive advantages. The increasing green consumers and eco-tourists in past years respond to the trend of environmental protection. Instead of thinking how to reduce costs and increase differentiation, environmental management is the primary step for ecotourism areas. Furthermore, the unique landscape and building patterns in ecotourism areas have them become distributive touring spots. In comparison with other touring spots, ecotourism areas could better attract foreign tourists. Managers of ecotourism areas are therefore suggested to pay attention to international marketing and foreign tourists so as to make tourism more convenient and meaningful.

3. The ideas of green consumption and even ecotourism are gradually proposed; however, not every visitor is willing to sacrifice the fun and comfort in the tours to respond to environmental protection. In addition to negatively conform to environmental measures, visitors should regard environmental protection as personal responsibility, possess environmental awareness, and engage in environmental consumption behaviors from daily life and education. It is also discovered in this study that the public with environmental awareness would not necessarily perform environmental consumption behaviors. The government, environmental managers, and even you and I should reflect to the elimination of the gap.

4. Environmental protection, environmental responsibility, perceived value, and local culture and natural ecology are the best strategies for sustainable green tourism. It could be the reference for the management strategy and plan design of bed and breakfast (B\&B).

\section{REFERENCES}

Bailey, S., \& Mattei, U. (2013). Social movements as constituent power: The Italian struggle for the commons. Indiana J. Global Leg. Stud., 20, 965-1013.

Boyd, D. R. (2012). The environmental rights revolution: A global study of constitutions, human rights, and the environment. Vancouver, British Columbia: UBC Press.

Chen, A., \& Peng, N. (2012). Green hotel knowledge and tourists' staying behavior. Ann. Tourism Res., 39(4), 22112219.

Chen, L. C., Lin, S. P., \& Kuo, C. M. (2013). Rural tourism: Marketing strategies for the bed and breakfast industry in Taiwan. Int. J. Hospit. Manage., 32, 278-286.

Chen, M. F., \& Tung, P. J. (2014). Developing an extended theory of planned behavior model to predict consumers' intention to visit green hotels. Int. J. Hospit. Manag., 36, 221- 230.

Cullinan, C. (2013). The rule of nature's law. In Rule of law for nature: New dimensions and ideas in environmental law (ed. C. Voigt). New York, NY: Cambridge University Press, 94-108. 
DeWaters, J. (2011). Energy literacy of secondary students in New York State (USA): A measure of knowledge, affect, and behavior. Energ. Pol., 39(3), 1699-1710.

Ellis, J. M. (2014). The sky's the limit: Applying the public trust doctrine to the atmosphere. Temple Law Rev., 86, 807-847.

Han, H. S., Hsu, L. T., \& Sheu, C. (2010). Application of the theory of planned behavior to green hotel choice: Testing the effect of environmental friendly activities. Tourism Manag., 31(3), 325-334.

He, H., \& Li, Y. (2010). Consumer evaluation of technology-based vertical brand extension. Eur. J. Market., 44(9/10), 1366-1383.

Hsueh, S. L. (2012) A fuzzy utility-based multi-criteria model for evaluating households' energy conservation performance: A Taiwanese case study. Energies, 5(8), 2818-2834.

Hsueh, S. L. (2015). Assessing the effectiveness of community-promoted environmental protection policy by using a Delphi-fuzzy method: A case study on solar power and plain afforestation in Taiwan, Renew. Sust. Energ. Rev., 49, 1286-1295.

Icek, A., J. Nicholas, S. Sana, \& Nicole, G. C. (2011). Knowledge and the prediction of behavior: The role of information accuracy in the theory of planned behavior. Basic Appl. Soc. Psychol., 33(2), 101-117.

Jamal, T. B. (2011). Virtue ethics and sustainable tourism pedagogy: Phronesis, Principles and Practice. J. Sustain. Tourism, 12(6), 530-545.

Kapoor, T. (2015). Is successful water privatization a pipe dream? An analysis of three global case studies. Yale J. Int. Law, 40, 157-192.

Kill, J. (2014). Economic valuation of nature: The price to pay for conservation? Retrieved from http://www.rosalux.de/fileadmin/rls_uploads/pdfs/sonst_publikationen/Economic-Valuation-ofNature.pdf

Kim, Y., Yun, S., \& Lee, J. (2014). Can companies induce sustainable consumption? The impact of knowledge and social embeddedness on airline sustainability programs in the U.S. Sustainability, 6, 3338-3356.

Koller, M., Floh, A., \& Zauner, A. (2011). Further insights into perceived value and consumer loyalty: A "green" perspective. Psychol. Market., 28, 1154-1176.

Kravchenko, S., Chowdhury, T. M. R., \& Bhuiyan, M. J. H. (2013). Principles of international environmental law. In Routledge handbook of international environmental law (ed. S. Alam, M. J. H. Bhuiyan, T. M.R. Chowdhury, \& E. J. Techera). New York, NY: Routledge, 43-60.

Küker, O. (2012). The effects of consumer' environmental responsibilities towards attitudes of the green advertising: A sample in Eskisehir. J. Yasar Univ., 26(7), 4505-4525.

Laitos, J. G. (2012). The right of nonuse. New York, NY: Oxford University Press.

Mudd, M. B. (2011). A "constant and difficult task": Making local land use decisions in states with a constitutional right to a healthful environment. Ecol. Law Q., 38, 1-62.

Munro, G. S. (2012). The public trust doctrine and the Montana Constitution as legal bases for climate change litigation in Montana. Montana Law Rev, 73, 123-160.

O'Dea, E. (2014). Reviving California's public trust doctrine and taking a proactive approach to water management, just in time for climate change. Ecol. Law Q., 41, 435-460.

Pikturnienè, I., \& Mackelaitè, A. (2013). Attitude formation towards local and international ecological face and body care brands among Lithuanian female consumers. Organ. Mark. Emerg. Econ., 4(1), 23-42.

Pradeep, J. (2012). Effect of environmental concern \& social norms on environmental friendly behavioral intentions. Bus. Intell. J., 5(1), 169-175.

Stone, C. D. (2010). Should trees have standing? Law, morality, and the environment (3rd ed.). New York, NY: Oxford University Press.

Voigt, C. (Ed.). (2013). Rule of law for nature: New dimensions and ideas in environmental law. New York, NY: Cambridge University Press.

Wager, K. W. K. (2014). In common law we trust: How Hawaii's public trust doctrine can support atmospheric trust litigation to address climate change. Hastings West-Northwest J, Environ, Law, Policy, 20, 55-106.

Wallace, G., \& Russell, A. (2004). Eco-cultural tourism as a means for the sustainable development of culturally marginal and environmentally sensitive regions. Tourist Stud., 4(3), 235-254.

Wells, V. K., Ponting, C. A., \& Peattle, K. (2011). Behaviour and climate change: Consumer perceptions of responsibility. J. Market. Manag., 27(7-8), 808-833. 
Wood, M. C. (2014). Nature's trust: Environmental law for a new ecological age. New York, NY: Cambridge University Press.

Wray-Lake, L., Flanagan, C. A., \& Osgood, D. W. (2010). Examining trends in adolescent environmental attitudes, beliefs and behaviors across three decades. Environ. Behav., 42(1), 61-85.

Wyman, J. B. (2010). In States we trust: The importance of the preservation of the public trust doctrine in the wake of climate change. Vermont Law Rev., 35, 507-514.

Young, W., Hwang, K., McDonald, S., \& Oates, C. (2010). Sustainable consumption: Green consumer behaviour when purchasing products. Sustain. Dev., 18(1), 20-31.

\section{http://www.ejmste.com}

